Pacific Journal of Mathematics

A SUB-ELLIPTIC ESTIMATE FOR A CLASS OF INVARIANTLY 


\title{
A SUB-ELLIPTIC ESTIMATE FOR A CLASS OF INVARIANTLY DEFINED ELLIPTIC SYSTEMS
}

\author{
L. M. Sibner AND R. J. SibneR
}

We consider a certain invariantly defined nonlinear system of partial differential equations on a Riemannian manifold. Since a special case describes a steady, irrotional, compressible flow on the manifold, it is natural to refer to the (square of) the pointwise norm of the solution as the speed of the flow and to the density of the flow. Under appropriate restrictions on the density, the system is elliptic and we obtain a sub-elliptic estimate and a maximum principle for the speed of the flow in terms of the curvature of the manifold.

Introduction. Let $M$ be an $n$-dimensional Riemannian manifold, and $\Lambda^{p}(M)$ the space of smooth $p$-forms on $M$. For $\omega \in \Lambda^{p}(M), x \in M$, let $Q(\omega)=(\omega, \omega)(x)={ }^{*}\left(\omega \wedge^{*} \omega\right)(x)$ denote the pointwise norm of the form $\omega$. Let $\rho: C^{\infty}(M) \rightarrow R$ be a given bounded smooth strictly positive function which we call the density function.

In the following, we consider the invariantly defined nonlinear system of equations for $\omega \in \Lambda^{p}(M)$ :

$$
\begin{aligned}
d \omega & =0 \\
\delta(\rho(Q(\omega)) \omega) & =0 .
\end{aligned}
$$

If $p=1$, this system describes the motion of a compressible fluid on $M$ and reduces to a single second order equation for the potential function. If the metric is Euclidean and $\rho(Q)=(1-(\gamma-1) / 2 Q)^{1 / \gamma-1}$, it becomes the gas dynamics equation for polytropic flow in $R^{n}$. If $\rho \equiv 1$, one obtains the Laplace-Beltrami equation.

To be more explicit, if $\omega$ is a solution of (1), then it is also a solution of a homogeneous second order quasi-linear system, $A \omega=0$. In local coordinates, let

$$
\omega=\omega_{i_{1} \cdots i_{p}} d x^{i_{1}} \wedge \cdots \wedge d x^{i_{p}}, \quad \omega^{j_{1} \ldots j_{p}}=g^{j_{1} i_{1}} \cdots g^{j_{p} p_{p}} \omega_{i_{1} \cdots i_{p}},
$$

and assume $\rho=\rho(Q(\omega))$. Then, $A: \Lambda^{p}(M) \rightarrow \Lambda^{p}(M)$ is given by

$$
\begin{aligned}
(A \omega)_{i_{1} \cdots i_{p}}=\sum_{i, j} g^{j i} & \left\{\rho \frac{\partial^{2} \omega_{i_{1} \cdots i_{p}}}{\partial x^{i} \partial x^{j}}\right. \\
& \left.+2 \rho^{\prime} \omega^{j_{1} \cdots j_{p}} \sum_{k=1}^{p} \omega_{i_{1} \cdots i_{k-1} i_{i} i_{k+1} \cdots i_{p}} \frac{\partial^{2} \omega_{j_{1} \cdots j_{p}}}{\partial x^{i_{k} \partial s^{j}}}\right\} \\
& + \text { lower order terms. }
\end{aligned}
$$

(We will observe the usual summation convention wherever possible.) 
A computation shows that the system (1) is elliptic for $\omega \in \Lambda^{p}(M)$ if and only if

$$
\frac{d}{d Q}\left(\rho^{2} Q\right)>0 \text { for all } x \in M
$$

If $M$ is compact and (1) is elliptic, there is a unique weak solution in each cohomology class (Sibner [7]). The question of smooth solutions is unresolved except in the case $p=1$ ([7]) or if the metric is Euclidean (Uhlenbeck [10]).

Assuming that the system (1) is elliptic, we shall derive an inquality for the function $Q$, of the following kind:

$$
L Q+B(\omega) \geqq 0
$$

where $\omega$ is a solution of (1), $L$ is a single second order elliptic operator with no zero order term, and $B$ is a quadratic form whose sign depends upon the curvature tensor. Such an inequality leads to a maximum principle and is perhaps a step in the direction of elliptic regularity for the system (1) (see [10]). An inequality of the form (3) and a maximum principle were previously proved by the authors for 1-forms on surfaces $(n=2)$ (see [9]).

1. The inequality satisfied by $Q$. Let $I=i_{1} \cdots i_{p}, J=j_{1} \cdots j_{p}$ be multi-indices and set $g^{I J}=g^{i_{1} j_{1}} \cdots g^{i_{p} j_{p}}$. Then, $Q(\omega)=g^{J l} \omega_{J} \omega_{I}$ in this notation. In terms of the Riemannian metric, let $|\nabla \omega|^{2}=$ $g^{k l} g^{J I} \nabla_{k} \omega_{J} \nabla_{l} \omega_{I}$. Define the curvature form (Lichnerowicz $[5,6]$ )

$$
K(\omega)=g^{J I} \omega_{J}\left\{\sum_{s=1}^{p} K_{i_{s}}^{t} \omega_{i_{1} \cdots t \cdots i_{p}}+\sum_{t<s}^{1 \cdots p} K_{i_{t} i_{s}}^{v u} \omega_{i_{1} \cdots v \cdots u i_{p}}\right\} .
$$

Computing the Laplacian of $Q$, one obtains

$$
-\frac{1}{2} \Delta Q=\frac{1}{2} g^{j i} \nabla_{j} \nabla_{i} Q=|\nabla \omega|^{2}+\left(g^{J J} \omega_{J}\right)\left(g^{j i} \nabla_{j} \nabla_{i} \omega_{I}\right)
$$

and using the formula for $\Delta \omega([11])$ one obtains the fundamental identity for $Q$ :

$$
-\frac{1}{2} \Delta Q=|\nabla \omega|^{2}+K(\omega)-p !(\omega, \omega)
$$

Next, let $\omega$ be a solution of (1) and replace $\omega$ in (1.1) by $\rho \omega$. Using the fact that $\delta \rho \omega=0$, one obtains

$$
-\frac{1}{2} \Delta\left(\rho^{2} Q\right)+p !(\delta d \rho \omega, \rho \omega)=\rho^{2} K(\omega)+|\nabla(\rho \omega)|^{2} .
$$

We shall show that the left hand side is a second order differ- 
ential operator on $Q, L Q=L_{1} Q+L_{2} Q$, and will compute its principal part.

$$
L_{1} Q=-\frac{1}{2} \Delta\left(\rho^{2} Q\right)=\frac{1}{2}\left(\rho^{2}+2 \rho \rho^{\prime} Q\right) g^{j i} \frac{\partial^{2} Q}{\partial x^{i} \partial x^{j}}+\text { first order terms } .
$$

Using the fact that $d \omega=0$,

$$
p !(\delta d \rho \omega)_{i_{1} \cdots i_{p}}=-g^{j i} \nabla_{j}\left(\rho^{\prime} \omega_{i_{1} \cdots i_{p}} \frac{\partial Q}{\partial x^{i}}-\rho^{\prime} \sum_{k=1}^{p} \omega_{i_{1} \cdots i_{k-1} i_{i}+1} \cdots i_{p} \frac{\partial Q}{\partial x^{i_{k}}}\right) .
$$

Therefore,

$$
\begin{aligned}
L_{2} Q & =p !(\delta d \rho \omega, \rho \omega) \\
& =-g^{j i} \rho \rho^{\prime} \omega_{i_{1} \cdots i_{p}} \omega^{i_{1} \cdots i_{p}} \frac{\partial^{2} Q}{\partial x^{i} \partial x^{j}}+g^{j i} \rho \rho^{\prime} \omega^{i_{1} \cdots i_{p}} \sum_{k=1}^{p} \omega_{i_{1} \cdots i_{k-1} i i_{k+1} \cdots i_{p}} \frac{\partial^{2} Q}{\partial x^{i_{k}} \partial x^{j}} \\
& + \text { first order terms. }
\end{aligned}
$$

Combining coefficients of $\partial^{2} Q / \partial x^{i} \partial x^{j}$,

$$
L_{2} Q=\left\{-g^{j i} \rho \rho^{\prime} Q+\rho \rho^{\prime} \omega_{i_{1} \cdots i_{p}} \sum_{k=1}^{p} g^{j i_{k} i_{1} \cdots i_{k-1} i i_{k+1} \cdots i_{p}}\right\} \frac{\partial^{2} Q}{\partial x^{i} \partial x^{j}}+\cdots
$$

and

$$
L Q=\left\{\frac{1}{2} g^{j i} \rho^{2}+\rho \rho^{\prime} \omega_{i_{1} \cdots i_{p}} \sum_{k=1}^{p} g^{j i_{k}} \omega^{i_{1} \cdots i_{k-1} i_{k+1} \cdots i_{p}}\right\} \frac{\partial^{2} Q}{\partial x^{i} \partial x^{j}}+\cdots .
$$

Proposition 1.1. If the system (1) is elliptic at a solution $\omega$, then $L$ is an elliptic operator.

Proof. The principal symbol of $L_{1}$ on a cotangent vector $\pi=$ $\left(\pi_{1}, \cdots, \pi_{n}\right) \neq 0$ is

$$
\frac{1}{2}\left(\rho^{2}+2 \rho \rho^{\prime} Q\right) g^{j i} \pi_{i} \pi_{j}>0
$$

using the ellipticity condition (2). Therefore, $L_{1}$ is elliptic.

Choose geodesic normal coordinates at a point, in which case $g^{i j}=\delta^{i j}, \omega^{I}=\omega_{I}$, and $Q(\omega)=\sum_{I}\left(\omega_{I}\right)^{2}$. The principal symbol of $L_{2}$ in these coordinates becomes:

$$
\begin{aligned}
& -\rho \rho^{\prime}\left(Q \delta^{i j}-\sum_{k=1}^{p} \omega_{i_{1} \cdots i_{k-1} j i_{k+1} i_{p}} \omega_{i_{1} \cdots i_{k-1} i i_{k+1} \cdots i_{p}}\right) \pi_{i} \pi_{j} \\
& =-\rho \rho^{\prime}\left\{\left(\sum\left(\omega_{i_{1} \cdots i_{p}}\right)^{2}\right)\left(\sum \pi_{i}^{2}\right)-\left(\sum_{k=1}^{p} \omega_{i_{1} \cdots i_{k-1} i i_{k+1} \cdots i_{p}} \pi_{i}\right)^{2}\right\} .
\end{aligned}
$$

If $\rho^{\prime} \leqq 0$, one sees immediately from the Schwartz inequality that this expression is nonnegative. Therefore, if $\rho^{\prime} \leqq 0$, the principal symbol of $L=L_{1}+L_{2}$ is positive definite and $L$ is elliptic. 
If $\rho^{\prime} \geqq 0$, the principal symbol of $L$ in geodesic normal coordinates is

$$
\frac{1}{2} \rho^{2} \sum \pi_{i}^{2}+\rho \rho^{\prime}\left(\sum \omega_{i_{1} \cdots i_{k-1} i i_{k+1} \cdots i_{p}} \pi_{i}\right)^{2}>0
$$

using the fact that $\rho$ is positive. Hence, $L$ is elliptic.

Summarizing the results of this section, we have shown

Proposition 1.2. Let $\omega \in \Lambda^{p}(M)$ be a solution of the homogeneous elliptic system (1). Then $Q(\omega)$ is a solution of the single scalar equation

$$
L Q=\rho^{2} K(\omega)+|\nabla(\rho \omega)|^{2}
$$

where $L$ is a second order elliptic operator having no zero order terms.

2. The maximum principle. Our main result is the following.

THEOREM. Let $\omega$ be a solution of the elliptic system (1). Then,

(a) $Q=(\omega, \omega)$ cannot have a relative maximum at a point $x_{0}$ where $\left.K(\omega)\right|_{x_{0}}>0$.

(b) If $Q$ has a relative maximum at a point $x_{0}$, in a neighborhood $N$ of which, $K(\omega) \geqq 0$ then

(i) $Q$ is constant on $N$.

(ii) $K(\omega) \equiv 0$ in $N$.

(iii) $\nabla \omega \equiv 0$ on $N$.

Proof. As in [9], statements (a) and (i) of (b) follow from Proposition 1.2 and the Hopf Maximum Principle. But if $Q$ is constant in $N$, then $L Q \equiv 0$ in $N$ which gives, again by Proposition 1.2 , statements (ii) and (iii).

If $p=1$, the curvature expression $K(\omega)$ reduces to $R^{i j} \omega_{i} \omega_{j}$ where $R^{i j}$ is the Ricci curvature tensor. One speaks of $R^{i j} \omega_{i} \omega_{j}$ as the Ricci curvature in the direction $\omega$. In the language of gas dynamics we have the

Corollary. A subsonic compressible flow on $M$ cannot assume its maximum speed at a point where the Ricci curvature is positive in the direction of the flow. If the maximum speed is attained at a point of a region $N$ in which the Ricci curvature in the flow direction is nonnegative, then the curvature must in fact be zero, the speed $Q$ must be constant, and the flow parallel in $N$ (i.e., the covariant derivatives, $\left.\nabla_{i} \omega_{j} \equiv 0\right)$. If it is further known that 
the Ricci curvature is positive definite, then $Q \equiv 0$ and hence $\omega \equiv 0$ in $N$.

Added in proof. The authors, with P. D. Smith, have obtained a regularity theorem for the system (1) using the estimate (3). It will appear in a forthcoming paper.

\section{REFERENCES}

1. L. Bers, Mathematical Aspects of Subsonic and Transonic Gas Dynamics, Wiley, New York, 1958.

2. S. Bochner, Vector fields and Ricci curvature, Bull. Amer. Math. Soc., 52 (1946), 776-797.

3. - Curvature and Betti numbers, Annals of Math., 49 (1948), 379-390.

4. E. Hopf, Elementare Bemerkungen über die Lösungen partieller Differentialgleichungen zweiter Ordnung vom elliptischen Typus, Sitzber. Preuss. Akad. Wiss. Physik-math. K1, 19 (1927),147-152.

5. A. Lichnerowicz, Courbure et nombres de Betti d'une varieté riemannienne compacte, Compt. Rend. Acad. Sci. Paris, 226 (1948), 1678-1680.

6. Courbure, nombres de Betti espaces symmetriques, Proc. Intern. Congr. of Math., 2 (1952), 216-223.

7. L. M. Sibner and R. J. Sibner, A nonlinear Hodge-de Rham theorem, Acta Math., 125 (1970), 57-73.

8. —_ Nonlinear Hodge theory: Applications, Advances in Math., 31 (1979), 1-16.

9. — A maximum principle for compressible flow, Proc. Amer. Math. Soc., 71 (1978), 103-108.

10. K. Uhlenbeck, Regularity for a class of nonlinear elliptic systems, Acta Math., 138 (1977), 219-240.

11. K. Yano, Integral formulas in Riemannian Geometry, Marcel Dekker, New York, 1970.

Received May 8, 1980. Research of the first author was partially supported by NSF Grant MCS78-03276 and research of the second author was partially supported by NSF Grant MCS78-03268.

Polytechnic Institute of New York

BROOKLYN, NY 11201

AND

City University of New York

Brooklin College

Brooklin, NY 11210 



\section{PACIFIC JOURNAL OF MATHEMATICS}

\section{EDITORS}

DONALD BABBITT (Managing Editor)

University of California

Los Angeles, CA 90024

Hugo RossI

University of Utah

Salt Lake City, UT 84112

C. C. MOORE and ANDREW OGG

University of California

Berkeley, CA 94720
J. DugundjI

Department of Mathematics

University of Southern California

Los Angeles, CA 90007

R. FINN and J. MILGRAM

Stanford University

Stanford, CA 94305

\section{ASSOCIATE EDITORS}
R. ARENS
E. F. BECKENBACH
B. H. NeUmanN
F. WOLF
K. YosHIDA

\section{SUPPORTING INSTITUTIONS}

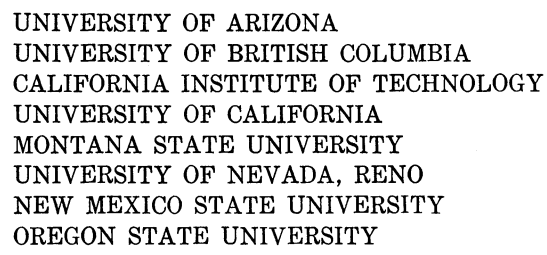

UNIVERSITY OF ARIZONA

UNIVERSITY OF BRITISH COLUMBIA CALIFORNIA INSTITUTE OF TECHNOLOGY

UNIVERSITY OF CALIFORNIA

MONTANA STATE UNIVERSITY

UNIVERSITY OF NEVADA, RENO

NEW MEXICO STATE UNIVERSITY OREGON STATE UNIVERSITY

\author{
UNIVERSITY OF OREGON \\ UNIVERSITY OF SOUTHERN CALIFORNIA \\ STANFORD UNIVERSITY \\ UNIVERSITY OF HAWAII \\ UNIVERSITY OF TOKYO \\ UNIVERSITY OF UTAH \\ WASHINGTON STATE UNIVERSITY \\ UNIVERSITY OF WASHINGTON
}

The Supporting Institutions listed above contribute to the cost of publication of this Journal, but they are not owners or publishers and have no responsibility for its content or policies.

Mathematical papers intended for publication in the Pacific Journal of Mathematics should be in typed form or offset-reproduced, (not dittoed), double spaced with large margins. Please do not use built up fractions in the text of the manuscript. However, you may use them in the displayed equations. Underline Greek letters in red, German in green, and script in blue. The first paragraph or two must be capable of being used separately as a synopsis of the entire paper. Please propose a heading for the odd numbered pages of less than 35 characters. Manuscripts, in triplicate, may be sent to any one of the editors. Please classify according to the scheme of Math. Reviews, Index to Vol. 39. Supply name and address of author to whom proofs should be sent. All other communications should be addressed to the managing editor, or Elaine Barth, University of California, Los Angeles, California, 90024.

50 reprints to each author are provided free for each article, only if page charges have been substantially paid. Additional copies may be obtained at cost in multiples of 50 .

The Pacific Journal of Mathematics is issued monthly as of January 1966. Regular subscription rate: $\$ 102.00$ a year (6 Vols., 12 issues). Special rate: $\$ 51.00$ a year to individual members of supporting institutions.

Subscriptions, orders for numbers issued in the last three calendar years, and changes of address shoud be sent to Pacific Journal of Mathematics, P.O. Box 969, Carmel Valley, CA 93924, U.S.A. Old back numbers obtainable from Kraus Per!odicals Co., Route 100, Millwood, NY 10546.

\section{PUBLISHED BY PACIFIC JOURNAL OF MATHEMATICS, A NON-PROFIT CORPORATION}

Printed at Kokusai Bunken Insatsusha (International Academic Printing Co., Ltd.). 8-8, 3-chome, Takadanobaba, Shinjuku-ku, Tokyo 160, Japan.

Copyright (C) 1981 by Pacific Jounal of Mathematics Manufactured and first issued in Japan 


\section{Pacific Journal of Mathematics}

Vol. 94, No. $2 \quad$ June, 1981

Thomas E. Armstrong and William David Sudderth, Nearly strategic

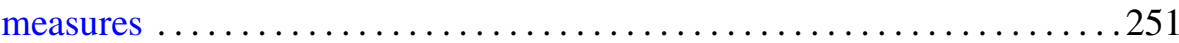

John J. Buoni, Artatrana Dash and Bhushan L. Wadhwa, Joint Browder

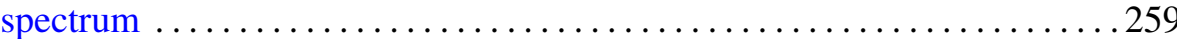

Jack Paul Diamond, Hypergeometric series with a $p$-adic variable . .......265

Raymond Frank Dickman, Jack Ray Porter and Leonard Rubin,

Completely regular absolutes and projective objects ............ 277

James Kenneth Finch, On the local spectrum and the adjoint ........... 297

Benno Fuchssteiner, An abstract disintegration theorem ............ 303

Leon Gerber, The volume cut off a simplex by a half-space $\ldots \ldots \ldots \ldots 311$

Irving Leonard Glicksberg, An application of Wermer's subharmonicity

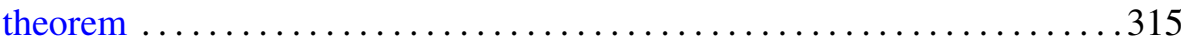

William Goldman, Two examples of affine manifolds ............... 327

Yukio Hirashita, On the Weierstrass points on open Riemann surfaces .....331

Darrell Conley Kent, A note on regular Cauchy spaces ............. 333

Abel Klein and Lawrence J. Landau, Periodic Gaussian

Osterwalder-Schrader positive processes and the two-sided Markov

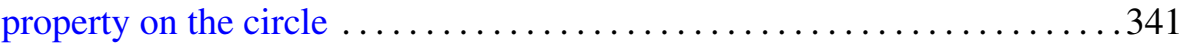

Brenda MacGibbon, $\mathscr{K}$-Borelian embeddings and images of Hausdorff

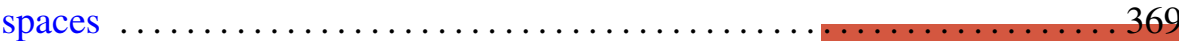

John R. Myers, Homology 3-spheres which admit no PL involutions . . . . . 379

Boon-Hua Ong, Invariant subspace lattices for a class of operators . . . . . 385

Chull Park, Representations of Gaussian processes by Wiener processes . . . 407

Lesley Millman Sibner and Robert Jules Sibner, A sub-elliptic estimate

for a class of invariantly defined elliptic systems $\ldots \ldots \ldots \ldots \ldots \ldots .417$

Justin R. Smith, Complements of codimension-two submanifolds. III.

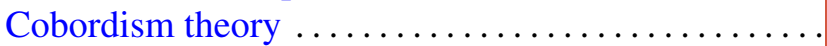

William Albert Roderick Weiss, Small Dowker spaces

David J. Winter, Cartan subalgebras of a Lie algebra and its ideals. II ... 